\title{
THE IMPACT OF A HIGH MAGNIFICATION APPROACH FOR TEETH PREPARATIONS ON THE MARGINAL FIT OF CAD/CAM MONOLITHIC LITHIUM DISILICATE CROWNS (IN VITRO STUDY)
}

\author{
Alaa M. Akmal ${ }^{1}{ }_{B D s}$, Yousreya A. Shalaby 2 PhD, Amir S. Azer 3 PhD. \\ ABSTRACT
}

INTRODUCTION: Marginal integrity is a challenging goal revealing an accurate restoration with definite marginal adaptation. Inflammation of gingival tissues and bone destruction correlate directly with a poor marginal property of the restoration. These days improved vision is essential in dentistry upgrading exactness and flawlessness.

OBJECTIVES: To assess the impact of amplification on the marginal adaptation of CAD/CAM monolithic lithium disilicate crowns.

MATERIALS AND METHODS: This in-vitro study was performed using 16 upper right cuspid typodont teeth; divided into two entities according to tooth preparation approach $(n=8)$. Group I, teeth preparation were done without magnification (control group), Group II, teeth preparation utilizing the dental operating microscope (DOM) under magnification of 16x. Optical impressions were taken through scanning by Sirona inEOS X5 extra-oral scanner, then full anatomical crowns were structured, processed, Sintered and glazed. CBCT was utilized to quantify the marginal gape distances before and after cementation/aging.

RESULTS: Marginal gaps were significantly increased after cementation and aging in both groups yet still inside the worthy minimal gap values. Group II demonstrated recognizable less marginal gaps.

CONCLUSIONS: Using the dental operating microscope with high magnifications improved the marginal fit of CAD-CAM lithium dislilicate crowns where less marginal gapes were noticed compared to the conventional approach which is without any magnifications.

KEYWORDS: Microscope, Fit, Cone beam, Monolithic, Lithium Disilicate.

RUNNING TITLE: Magnification and marginal fit of CAD/CAM glass-ceramics.

1 Dentist at ministry of health, Alexandria, Egypt.
2Professor of Fixed Prosthodontics, Conservative Dentistry, Faculty of Dentistry, Alexandria University, Alexandria, Egypt.

3Lecturer of Fixed Prosthodontics, Conservative Dentistry, Faculty of Dentistry, Alexandria University, Alexandria, Egypt.

* Corresponding Author:

E-mail:alaa_akmal@hotmail.com

\section{INTRODUCTION}

Marginal adaptation of a crown to its abutment is a trigger that impacts the endurance and competence of fixed prosthodontics. Marginal gaps may contribute to the progression of dental caries and periodontal diseases and may likewise prompt microleakage (1). In late decades, the patients' developing interest for profoundly natural-appearing restorations has led to the innovation of new all-ceramic materials with improved mechanical qualities guaranteeing a proper life span and limiting technical flaws (2).

Lithium disilicate (LD) material is a promising esthetic material with satisfactory mechanical properties. Machined ceramics are of outstanding natural appearance with flexural strength 350 Mpa (3) generally, it is to be veneered with fluoroapatite-based ceramics or utilized as one solid material in monolithic form (4).

Failure of restorations may occur due to marginal discrepancies bringing about cement exposure to the oral environment. This leads to cement disintegration causing microleakage which is the starting phase of defective restoration $(5,6)$.

Results of a recent in vitro study suggested that pressed and milled lithium disilicate SCs from digital impressions had a better internal fit to the abutment tooth than pressed SCs from polyvinylsiloxane impressions (7).

To date, in general, marginal and internal fit of lithium disilicate restorations is significantly influenced by the employed digital impression technique. Although almost all actual digital impression systems show accuracy values within the thresholds of clinical acceptability, significant fit discrepancies are still evident among different digital systems (8).

Clinically, most dental professionals won't have the option to see an open margin of less than $200 \mu \mathrm{m}(0.2 \mathrm{~mm})$. The film thickness of cement used in most crown and bridge restorations is $25 \mu \mathrm{m}(0.025 \mathrm{~mm})$, or well past the settling intensity of the naked eye (9).

The best strategy to gauge marginal opening stays a controversial topic. A few methods have been distinguished (for example simple direct investigation by probes and mirrors, 
reproduction strategy, light and scanning electron microscopy and small scale figured tomographic assessment) (10).

As innovation advanced, 3D checking systems are currently ready to create $3 \mathrm{D}$ recreated pictures giving a boundless number of segments and focuses for linear estimations in various ways on 3D information segments. These pictures could be captured utilizing optical scanners such as tripleexamine procedure or x-rays as cone-beam CT permitting high goals examination of the distance between tooth structure and the restoration (11).

The Operating Microscopy is an innovation that has fundamentally improved dental specialists' cognition of the dental apparatus. It gives a scope of amplification of $3 x$ to $25 x$ with a coaxial light source more grounded than a surgical headlamp (9).

There are numerous benefits of amplification gadgets for example; enhanced perception, improved working position and expanded referral. While a few disadvantages were accounted for as the adjustment time of the new workspace, the significant expense of the amplification gadget and its related auxiliaries, extra strides for infection control and the potential sharp damage at the workplace (12).

Few components are significant for thought in improving clinical representation, for example, stereopsis, amplification chains, the profundity of field, settling power, working separation, circular and chromatic bending (i.e., variation), ergonomics, eye fatigue, head and neck weariness, and cost (9).

This investigation was an attempt to evaluate the impact of high amplification approach on the minimal discrepancy of CAD/CAM solid lithium disilicate glass-ceramics using conebeam CT. The null hypothesis proposed was that the operating microscope (OM) did not improve the marginal fit of CAD/CAM ceramic crowns.

\section{MATERIALS AND METHODS}

The research was accomplished in the Department of Conservative Dentistry, Faculty of Dentistry, Alexandria University. The investigation was structured and applied on sixteen maxillary cuspid typodont teeth and divided into two groups.

Group I (control): Eight CAD/CAM monolithic ceramic crowns supported on abutment following conventional teeth preparation approach (without magnification).

Group II: Eight CAD/CAM monolithic ceramic crowns supported on abutment with teeth preparation following the dental operating microscope (KAPS, dental microscope) approach with a magnification of 16x.

Teeth were mounted in an interchangeable student working model one at a time to standardize the angulations and the phantom head was attached to the metal part of the chair head through ball and socket special device to fix it while preparation and before starting preparation, sectional indices were produced using an addition-cured silicone impression material as a preparation reference during tooth reduction.

A silicon index of unprepared teeth, into which contrasting colored silicon injected to occupy the space created by tooth preparation, was sectioned in the midline. Images of sectioned index were captured with optical microscope (Olympus model SZ-11, Japan) attached to a personal computer. A calibrated image analysis software was used to measure the depth of preparation (in millimeters) at five points (labial-cervical, mid-labial, incisal, mid-palatal and palatal cervical) (13).

Teeth were prepared following the guidelines of all ceramic tooth preparation; (incisal reduction: 1.5-2mm, proximal reduction: $1.5 \mathrm{~mm}$, incisal convergence: 6-15 degree) (14). Heavy chamfer finish line configuration $1 \mathrm{~mm}$ all around was accomplished using tapered round diamond burs (Komet, USA) with a polished guide pin, $0.5 \mathrm{~mm}$ in length and 0.18 $\mathrm{mm}$ in radius.

Guide pin was used for controlled tissue-protecting crown preparation were used as Guide pin as "horizontal distance keeper": to assure a controlled preparation with an even cutting depth. The $0.5 \mathrm{~mm}$ long guide pin as "vertical distance keeper": guaranteed that a pre-defined distance to the periodontium is kept safe during subgingival preparation without invading the biologic width (15).

\section{Crowns design and fabrication}

Optical impressions were taken for each prepared tooth in both groups inside the model, neighboring and opposing teeth were scanned utilizing an extra-oral scanner.

Emax CAD ceramic blocks (Ivoclar Vivadent, USA) were milled to full anatomical crowns using the Sirona MC X5 milling machine (Sirona Dental Systems, Bensheim, Germany) followed by crystallization, and glazing.

Tests Prior to cementation, the marginal adaptations of CAD/CAM lithium disilicate crowns onto their corresponded abutments were examined using cone-beam CT machine J.Morita R100 cone beam 3D imaging system (Morita 3DX; J Morita Mfg corp., Kyoto, Japan.). The scan was done with field of view (FOV) $100 \mathrm{~mm} \mathrm{X} \mathrm{H} \mathrm{80mm.} \mathrm{The} \mathrm{volume} \mathrm{was}$ reconstructed with $0.260 \mathrm{~mm}$ isometric voxel size. The tube voltage was $90 \mathrm{kVp}$ and $8 \mathrm{~mA}$, Exposure time was 20 seconds. Then CBCT was utilized again to assess the progression influenced by the cementation, aging strategies and simulating oral conditions (16).Vertical and horizontal gap measurements in two sections, sagittal and coronal respects the four zones of each crown (sagittal labial, sagittal palatal, coronal mesial and coronal distal) (11). (Figure 1, 2)

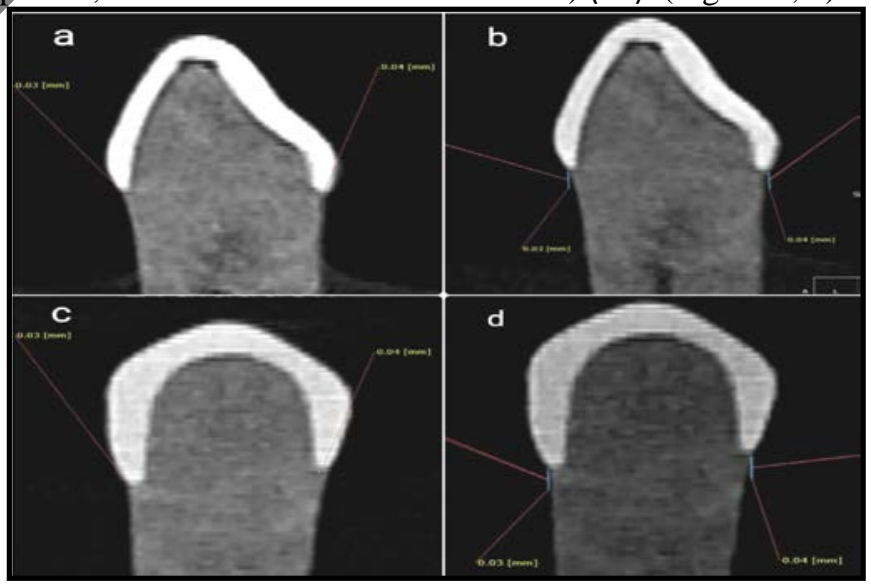

Figure (1): CBCT before cementation a) Vertical gap measurements in a sagittal segment. b) horizontal gap measurements in a sagittal segment. c) vertical gap 
measurements in a coronal segment. d) horizontal gap measurements in a coronal segment.
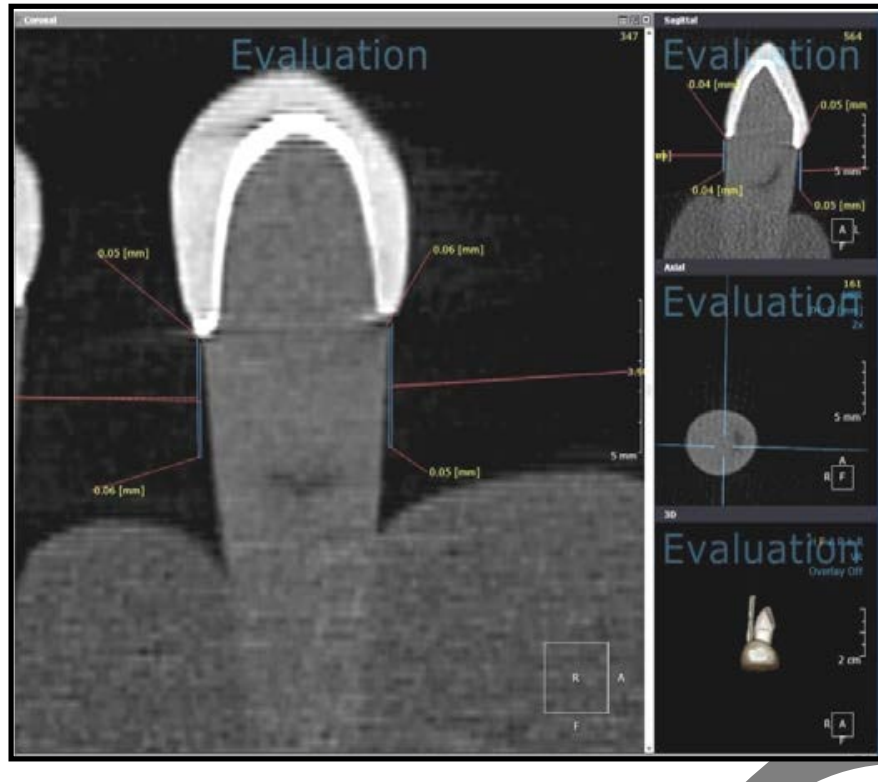

Figure (2):CBCT software 3D, vertical and horizontal measurements in coronal and sagittal segments after cementation and aging.

Cementation The internal surfaces of the crowns were treated with hydrofluoric K-etchant for $90 \mathrm{sec}(17)$, altogether washed out and dried with oil-free air (18) then Salinization using a Ceramic Primer for 30 sec. ( Bisco, Inc. 1100W, U.S.A.)

Then the crowns were cemented onto their relating abutments of each group with the self-etch, self-cure resin cement (Multilink Automix) following the manufacturer's instructions, under a static load of $5 \mathrm{~kg}$ (19).

Aging of the specimens after cementation specimens were subjected to 500 thermal cycles corresponding to six months of clinical service using a custom made thermo-cycling machine (custom made in dental biomaterials department, faculty of dentistry, Alexandria University). Warm cycles were performed precisely with a machine that moves the specimens between two temperature-controlled water shower (the shower temperatures were balanced at $5^{\circ} \mathrm{C}$ and $55^{\circ} \mathrm{C}$ with a dwell time of one second in each shower and unwinding time of 30 seconds in the air between the two showers) (20). They were then exposed to 120,000 cyclic stacking of burden up to $50 \mathrm{~N}$ (21) resembling a half year of intraoral service.

Statistical analysis

The Student t-test was utilized to compare between the two groups for ordinarily dispersed quantitative factors while the Paired t-test was surveyed for examination between various periods. The significance of the obtained results was judged at the confidence level of $5 \%$.

\section{RESULTS}

The mean and SD values of both tests were statistically significant with $\mathrm{P}<0.001^{*}$ and still within the accepted range of clinical marginal gap. Marginal gap distances were significantly increased after cementation and aging processes in both groups of both coronal and vertical sections. (Table1)
Table (1): Comparison between marginal gap distances $(\mu \mathrm{m})$ before cementation and after cementation and aging in both sagittal and coronal sections

\begin{tabular}{|c|c|c|c|c|c|}
\hline & & Before & After & $\mathbf{t}$ & $\mathbf{P}$ \\
\hline \multirow{5}{*}{ 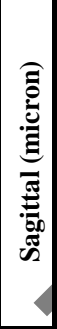 } & V & & & & \\
\hline & $\begin{array}{l}\text { Group I } \\
(n=8)\end{array}$ & $93.1 \pm 8.43$ & $103.8-7.91$ & 9.379 & $<0.001^{*}$ \\
\hline & $\begin{array}{l}\text { Group II } \\
(\mathrm{n}=8)\end{array}$ & $36.25 \pm 2.31$ & $43.75 \pm 3.54$ & $7.937^{*}$ & $<0.001^{*}$ \\
\hline & $\begin{array}{l}\text { Group } \\
(\mathrm{n}=8)\end{array}$ & $95.63 \pm 9.80$ & $100.0 \pm 9.26$ & $2.966^{*}$ & $0.021^{*}$ \\
\hline & $\begin{array}{l}\text { Group } \\
(n=8)\end{array}$ & $36.25 \pm 2.31$ & $40.0 \pm 2.67$ & $3.000^{*}$ & $0.020^{*}$ \\
\hline \multirow{5}{*}{ 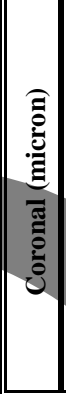 } & V & & & & \\
\hline & $\begin{array}{l}\text { Group I } \\
(n=8)\end{array}$ & & $103.1 \pm 7.99$ & $6.110^{*}$ & $<0.001^{*}$ \\
\hline & $\begin{array}{l}\text { Group II } \\
(n=8)\end{array}$ & & 54 & $3.989^{*}$ & $0.005^{*}$ \\
\hline & $\begin{array}{l}\text { Group I } \\
(n=8)\end{array}$ & & & $3.416^{*}$ & $0.011^{*}$ \\
\hline & $\begin{array}{l}\text { Group I } \\
(\mathrm{n}=8)\end{array}$ & $36.25 \pm 2.31$ & $32 \pm 4.17$ & $2.497^{*}$ & $0.041^{*}$ \\
\hline
\end{tabular}

Data was expressed by using mean \pm SD.

t: Paired t-test

$\mathrm{p}$ : $\mathrm{p}$ value for comparing between the studied periods

$*$ : Statistically significant at $\mathrm{p} \leq 0.05$

Group II showed less marginal gap distances in the sagittal section of the vertical measures with mean and SD values of $(36.25 \pm 2.31 \mu \mathrm{m})$ before cementation and $(43.75 \pm 3.54 \mu \mathrm{m})$ after cementation and aging while Group I showed a mean and SD values of $(93.1 \pm 8.43 \mu \mathrm{m})$ prior to cementation and of $(103.8 \pm 7.91 \mu \mathrm{m})$ after cementation and aging in same section. (Table 2) (Figure 3)

Table (2):Comparison between the marginal gaps $(\mu \mathrm{m})$ of the two studied groups in sagittal and coronal sections before and after cementation

\begin{tabular}{|c|c|c|c|c|c|}
\hline & & $\begin{array}{c}\text { Group I } \\
(\mathbf{n}=\mathbf{8})\end{array}$ & $\begin{array}{l}\text { Group II } \\
(\mathbf{n}=\mathbf{8})\end{array}$ & $\mathbf{T}$ & $\mathbf{p}$ \\
\hline & $\begin{array}{r}\text { Before } \\
\text { V } \\
\text { H } \\
\end{array}$ & $\begin{array}{c}93.1 \pm 8.43 \\
95.63 \pm 9.80 \\
\end{array}$ & $\begin{array}{l}36.25 \pm 2.31 \\
36.25 \pm 2.31 \\
\end{array}$ & \begin{tabular}{|l|}
$18.412^{*}$ \\
$16.682^{*}$ \\
\end{tabular} & $\begin{array}{l}<0.001^{*} \\
<0.001^{*}\end{array}$ \\
\hline is & $\begin{array}{r}\text { After } \\
\mathbf{V} \\
\mathbf{H} \\
\end{array}$ & $\begin{array}{l}103.8 \pm 7.91 \\
100.0 \pm 9.26 \\
\end{array}$ & $\begin{array}{c}43.75 \pm 3.54 \\
40.0 \pm 2.67 \\
\end{array}$ & \begin{tabular}{|l|}
$19.596^{*}$ \\
$17.611^{*}$ \\
\end{tabular} & $\begin{array}{l}<0.001^{*} \\
<0.001^{*}\end{array}$ \\
\hline 氞 & $\begin{array}{r}\text { Before } \\
\text { V } \\
\text { H } \\
\end{array}$ & $\begin{array}{l}93.13 \pm 7.99 \\
95.63 \pm 7.29 \\
\end{array}$ & $\begin{array}{r}35.0 \pm 3.78 \\
36.25 \pm 2.31 \\
\end{array}$ & \begin{tabular}{|l|}
$18.600^{*}$ \\
$21.960^{*}$ \\
\end{tabular} & $\begin{array}{l}<0.001^{*} \\
<0.001^{*}\end{array}$ \\
\hline & $\begin{array}{r}\text { After } \\
\text { V } \\
\text { H } \\
\end{array}$ & $\begin{array}{r}103.1 \pm 7.99 \\
98.75 \pm 7.44 \\
\end{array}$ & $\begin{array}{l}41.25 \pm 3.54 \\
40.62 \pm 4.17 \\
\end{array}$ & \begin{tabular}{|l|}
$20.030^{*}$ \\
$19.273^{*}$ \\
\end{tabular} & $\begin{array}{l}<0.001^{*} \\
<0.001^{*}\end{array}$ \\
\hline
\end{tabular}

Data was expressed by using mean \pm SD.

t: Student t-test

p: p value for comparing between the studied groups

*: Statistically significant at $\mathrm{p} \leq 0.05$ 


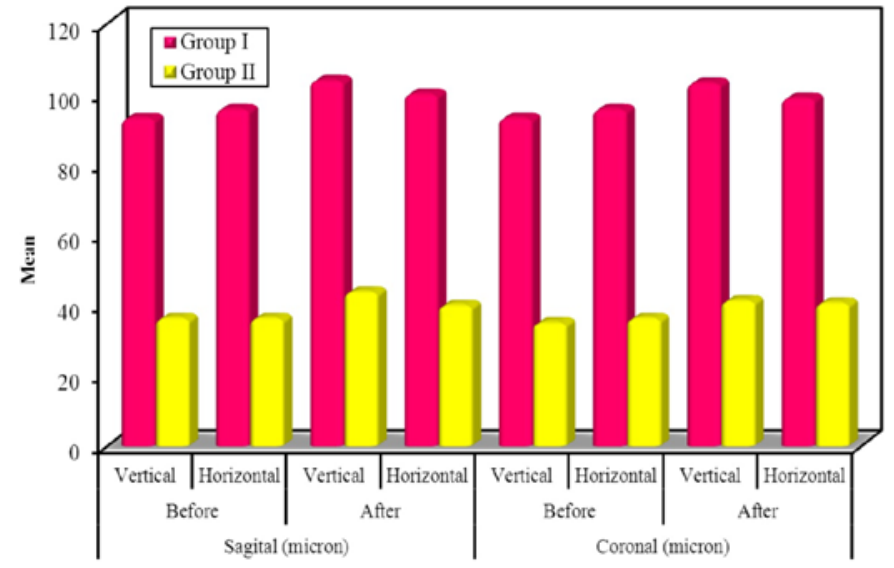

Figure (3):studied groups before and after cementation in sagittal and coronal sections.

\section{DISCUSSION}

Lithium disilicate in the most recent years has gained increased popularity in the dental field, offering miraculous advantages (22). Monolithic restorations have become progressively more well-known in the most recent years, lessening frequent complexities like chippings and cracks (23). Dental adhesives should guarantee adequate marginal adaptation and improve the fracture resistance of all-ceramics (21). McLean (24) suggested that the farthest limit for clinically acceptable marginal discrepancies ought to be 120 $\mu \mathrm{m}$. Poor marginal fit can bring about cement disintegration, microleakage and secondary decay (25).

This study was conducted to assess the impact of using the dental operating microscope with a high magnification range for teeth preparations on the marginal fit of CAD/CAM lithium disilicate glass-ceramic crowns.

Using a high magnification is extremely beneficial in producing precision in endodontics, surgical dental treatment, and even restorative dentistry especially when it comes to crown margins and marginal adaptation requiring resolution well beyond the $0.2 \mathrm{~mm}$ limit of human sight (9).

Optical impressions were taken through the Sirona inEOS X5 extra-oral scanner as several studies demonstrated that restorations fabricated from digital impressions were equally or more accurate than those produced by traditional impression materials (26)

Vertical and horizontal gap measurements were investigated by CBCT in two sections, sagittal and coronal respects the four zones of each crown (sagittal labial, sagittal palatal, coronal mesial and coronal distal) (27). Cone-beam Computed Tomography (CBCT) is a non-destructive method that does not require sectioning. It is a reliable tool for linear measurements that is known for its precision and assorted clinical utility Which allow accurate resolution images with low radiation exposure and short scanning time (28).
Prior to cementation, the marginal adaptations of CAD/CAM lithium disilicate crowns onto their corresponded abutments were examined using cone-beam CT.

It is hypothesized that the observed increase in the marginal gap after crystallization firing of lithium disilicate crowns is due to shrinkage accompanying the densification of the ceramic material during the additional heating stage but still within the clinically acceptable limit for marginal discrepancies of $120 \mu \mathrm{m}$ (29). Moreover, warm handling can impact crystallization energy, crystalline microstructure, and quality of lithium disilicate rebuilding efforts (30).

Data from this study revealed that marginal gap distances were significantly increased after cementation and aging in both groups of both coronal and vertical segments with $\mathrm{p}$ $<0.001^{*}$ yet within the clinically acceptable range of marginal gap. These results were convenient with Elguindy et al. (20) as the means, standard deviation values and results of paired t-test of the vertical marginal gap distances revealed that there was a

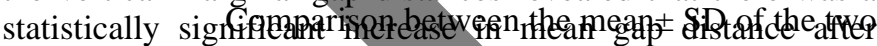
cementation in all groups.

Results concerning vertical and horizontal misfit indicated significant contrasts between the two groups either before cementation or even after cementation and aging. As group II indicated less vertical marginal gap distances with mean and SD values of $(36.25 \pm 2.31 \mu \mathrm{m})$ before cementation and $(43.75 \pm 3.54 \mu \mathrm{m})$ after cementation and aging while group I indicated relative increase in vertical marginal gaps comparing to group II with a mean and SD estimations of $(93.1 \pm 8.43$ $\mu \mathrm{m})$ before cementation and of $(103.8 \pm 7.91 \mu \mathrm{m})$ after cementation and aging.

Studies revealed that marginal discrepancies in the range of $100 \mathrm{pm}$ seem to be clinically acceptable with regard to longevity of the restorations. Others claimed that marginal discrepancies exceeding $100 \mathrm{pm}$ are clinically inadequate. (31).

The null hypothesis was rejected as the use of the operating microscope OM has helped in achieving a standardized marginal fit of CAD/CAM glass-ceramics with a clinically acceptable marginal gap range (32).

\section{CONCLUSIONS}

Inside the impediments of this investigation, it could be inferred that:

1. The operating microscopy OM produced restorations with significantly smaller marginal gaps.

2. Preparation utilizing a high magnification and digital technologies indicated less marginal discrepancies with statistically significant difference compared to conventional preparation.

\section{CONFLICT OF INTEREST}

The authors declare that they have no conflicts of interest.

\section{REFERENCES}

1. Oilo M, Gjerdet NR, Tvinnereim HM. The firing procedure influences properties of a zirconia core ceramic. Dent Mater. 2008;24:471-5.

2. Zarone F, Ferrari M, Mangano FG, Leone R, Sorrentino R. "Digitally Oriented Materials": Focus on Lithium Disilicate Ceramics. Int J Dent.2016:9840594. 
3. Fabbri G, Zarone F, Dellificorelli G, Cannistraro G, De Lorenzi M, Mosca A, et al. Clinical evaluation of 860 anterior and posterior lithium disilicate restorations: retrospective study with a mean follow-up of 3 years and a maximum observational period of 6 years. Int $\mathrm{J}$ Periodontics Restorative Dent. 2014;34:165-77.

4. Conrad HJ, Seong WJ, Pesun IJ. Current ceramic materials and systems with clinical recommendations: a systematic review. J Prosthet Dent. 2007;98:389-404.

5. Karlsson S. The fit of Procera titanium crowns. An in vitro and clinical study. Acta Odontol Scand. 1993;51:129-34.

6. May KB, Russell MM, Razzoog ME, Lang BR. Precision of fit: the Procera AllCeram crown. J Prosthet Dent. 1998;80:394-404.

7. Alfaro DP, Ruse ND, Carvalho RM, Wyatt CC. Assessment of the Internal Fit of Lithium Disilicate Crowns Using Micro-CT. J Prosthodont. 2015;24(5):381-6.

8. Schaefer O, Decker $M$, Wittstock F, Kuepper $H$, Guentsch A. Impact of digital impression techniques on the adaption of ceramic partial crowns in vitro. J Dent. 2014;42:677-83.

9. Carr GB, Murgel CAF. The use of the operating microscope in endodontics. Dent Clin North Am. 2010;54:191-214.

10. Beschnidt SM, Strub JR. Evaluation of the marginal accuracy of different all-ceramic crown systems after simulation in the artificial mouth. $\mathrm{J}$ Oral Rehabil.1999;26:582-93.

11. Darwish HA, Salah TS, Dimeery AG. Internal fit of lithium disilicate and resin nano-ceramic endocrowns with different preparation designs. FDJ. 2017;1: 67-72.

12. Low JF, Mohd Dom TN, Baharin SA. Magnification in endodontics: A review of its application and acceptance among dental practitioners. Eur J Dent. 2018;12:610-6.

13. Ram HK, Shah RJ, Agrawal HS. Eyaluation of three different tooth preparation techniques for metal ceramic crowns by comparing preparation depths: An in vitro study. J Indian Prosthodont Soc. 2015;1:162-7.

14. Gehrt M, Wolfart S, Rafai N, Reich S, Edelhoff D. Clinical results of lithium-disilicate crowns after up to 9 years of service. Clin Oral Invest 2013;17:275-84.

15. Komet USA - Burs \& Rotary Instruments for Dental Surgery. Available at: https://www.kometusa.com/V2/us/Products/DentalSurgery/Category/Diamond/Pin-Diamonds/856P.aspx

16. Elmagd AAAA, Abdel Bary SK. Evaluation of marginal gap of zirconium crown after aging cycle of thermoplastic resin clasp. In 2015.

17. BISCO Dental Documents | BISCO Dental [Internet]. [cited 2020 Feb 9]. Available from: https://www.bisco.com/documents/?CategoryId=1

18. Kelly JR, Rungruanganunt P, Hunter B, Vailati F. Development of a clinically validated bulk failure test for ceramic crowns. J Prosthet Dent. 2010;104:228-38.
19. Orsi IA, Varoli FK, Pieroni CHP, Ferreira MCCG, Borie E. In vitro tensile strength of luting cements on metallic substrate. Braz Dent J. 2014;25:136-40.

20. Elguindy JF, Mostafa DH, Agroudi MA. Margin assessment and fracture resistance of adhesively luted ceramic crowns. J Am Sci. 2010;6:264-73.

21. Kern M, Sasse M, Wolfart S. Ten-year outcome of three-unit fixed dental prostheses made from monolithic lithium disilicate ceramic. J Am Dent Assoc. 2012;143:234-40.

22. Raptis NV, Michalakis KX, Hirayama H. Optical behavior of current ceramic systems. Int J Periodontics Restorative Dent. 2006;26:31-41.

23. Pavan S, dos Santos PH, Berger S, Bedran-Russo AKB. The effect of dentin pretreatment on the microtensile bond strength of self-adhesive resin cements. J Prosthet Dent. 2010;104:258-64.

24. McLean JW, von Fraunhofer JA. The estimation of cement film thickness by an in vivo technique. Br Dent J. 1971;131:107-11.

25. Bindl A, Mörmann WH. Marginal and internal fit of allceramic CAD/CAM crown-copings on chamfer preparations. J Oral Rehabil. 2005;32:441-7.

26. Henkel GL. A comparison of fixed prostheses generated from conventional vs digitally scanned dental impressions. Compend Contin Educ Dent.2007;28:4224, 426-8, 430-1.

27. Holmes JR, Sulik WD, Holland GA, Bayne SC. Marginal fit of castable ceramic crowns. J Prosthet Dent. 1992;67:594-9.

28. Kumar M, Shanavas M, Sidappa A, Kiran M. Cone beam computed tomography - Know its secrets. J Int Oral Health 2015;7:64-8.

29. Alkumru H, Hullah WR, Marquis PM, Wilson HJ. Factors affecting the fit of porcelain jacket crowns. $\mathrm{Br}$ Dent J. 1988;164:39-43.

30. Lien W, Roberts HW, Platt JA, Vandewalle KS, Hill TJ, Chu T-MG. Microstructural evolution and physical behavior of a lithium disilicate glass-ceramic. Dent Mater. 2015;31:928-40.

31. Aboudorra HA, Amr H, Hafez A, Hassan AA. Internal fit evaluation of all ceramic restoration fabricated by two CAD/CAM milling systems using cone beam CT (CBCT). 65:13.

32. Selden HS. The role of a dental operating microscope in improved nonsurgical treatment of 'calcified' canals. Oral Surg Oral Med Oral Pathol. 1989;68:93-8. 